\title{
Strategic Alignment Role in Achieving the Organizational Excellence Through Organizational Dexterity - Analytical Study of the Opinions of a Sample of Professors at Colleges of Karbala University
}

\author{
AL-ZALEMY Mohamed Gabaar Hadi ${ }^{1}$, AL-SHERIF Ali Khadim Hussien², \\ BANNAY Dheyaa Falih ${ }^{3}$
}

${ }^{I}$ The Middle Euphrates University, Technical Institute, Karbala (IRAQ)

${ }^{2}$ The Middle Euphrates University, Technical Institute, Karbala (IRAQ)

${ }^{3}$ University of Warith Alanbiyaa, College of Management and Economics (IRAQ)

Email:Mo.1968m@yahoo.com

\begin{abstract}
The current research aims to reveal the strategic alignment role and its dimensions (communication, governance, infrastructures, Partnership, skills) in order to achieve the organizational excellence through organizational dexterity, so some colleges of Karbala University have been chosen. Given that, the research problem is crystallized by some intellectual and applied questions looking forward to being answered through determining its level of importance, impacts and the possibility of achieving the strategic alignment in the researched colleges. The questionnaire form was designed as a means to get data and information. The researcher adopted the descriptive analytical method that includes three variables which are: the strategic alignment, the organizational excellence, and the organizational dexterity that was used for strengthening and enhancing these concepts by concentrating on professors by choosing an Intentional sample included 80 professors in the under-examination colleges. The data analyzing was occurred through a group of statistical techniques such as (SPSS V.23). One of the most significant inclusions that the researchers found out is that the strategic alignment represents a group of attitudes and qualities seeking to innovation and changing to find out new tracks in discovering and investing the available energies. One of the most important recommendations was creating a new social reality in order to overcome conflicts and contradictions by excellence in providing the individual freedom and cooperative work to get benefit from its current capacities.
\end{abstract}

Keywords: strategic alignment, organizational excellence, and organizational dexterity

JEL: L26

UDK: 005.336.1:378.1(567)

005.332:005.322

\section{Introduction}

Institutions of higher education in Iraq face many challenges resulted from the accelerating changes in Iraq and in all fields, especially political, economical, social, and technological fields, that arose within the last years. These educational institutions require achieving the strategic alignment in their educational activities and programs as appropriate to the changes in order to meet their requirements to be capable of achieving the dynamic alignment with its 
environment and spreading the spirit of agreement and consistency between the coworkers, in addition to working in continuous harmony to communicate with customers, business partners and committees responsible for organizing work. The strategic alignment in all fields, including the work environment, contributes in eliminating the work problems, besides making the work times funnier and more comfortable, rather than provide calm and stable circumstances and deep impressions and emotions to deal with these challenges and conditions. The organizational dexterity is an essential factor for competition between organizations as they help in finding out opportunities and invest them perfectly to achieve excellence and sustainability. On the other hand, seeking for excellence in any educational institution is a primarily demand within the world environmental and competitive changes.

Thus, these institutions have to adopt an administrative and strategic philosophy enabling them to enhance the institutional reality and overcome the difficulties, as well as, make a tangible change in the performance which results in sustainability and competition. Based on that, this research carried out to reveal the strategic alignment role in achieving the organizational excellence in the researched colleges through the medium variant, the organizational dexterity. In order to achieve the content, a sample consisting of 80 professors in the under examination colleges was chosen; the research was divided into four themes: the first theme was about the research methodology, while the second theme was devoted to theoretical framework, the third theme was allocated to the practical side, and the research was concluded by the fourth theme that includes conclusions and recommendations.

\section{Research Methodology}

This theme is about recognizing the research problem and its importance, aims, the hypothetical model and hypotheses which are:

\section{Firstly: Research Problem}

Achieving the strategic alignment in the internal and external work environment of the organizations is one of the fundamental components in achieving the organizational excellence, and the incompatible work environment results in disrupted relations, disappointed connections, as well as, inability to invest opportunities and face challenges and consequently leads to breakdown and exclusion. Achieving the strategic alignment contributes in achieving stable organizational work environment which reflects on the abilities of these organizations to outperform highly efficient through the organizational dexterity.

\section{The Problem Lies in the Light of the Following Questions:}

1. Is there a clear perception about the strategic alignment of the researched organization?

2. To what extent does strategic alignment contribute in achieving organizational excellence in the researched colleges?

3. Is there an impact of strategic alignment on achieving organizational excellence through organizational dexterity?

\section{Secondly: Research Importance}

1. The research importance results from the importance of the three discussed variables as the strategic alignment, the organizational excellence and the organizational dexterity are necessary for viability and continuity of the business organizations and they are the keys of their success within the dynamic business environment as they enable these organizations to control and adapt with the sudden environmental changes. 
2. Drafting several plans and strategies that may provide the administrative strategic alignment techniques with means of interaction among people inside the organization that strengthens the organizational excellence.

3. The research importance resulted from the organizational dexterity techniques that the organization may achieve by depending on the components of the strategic alignment as it guides anything that may achieve the organizational excellence.

4. Recognizing all the conditions that surround the strategic alignment variable and that increase the excitement level of performance in order to eliminate the red tape.

\section{Thirdly: Research Objectives}

This research seeks to achieve a group of objectives such as:

1. Working on strengthening and supporting the strategic alignment techniques through effective communications, adopting partnership principles in taking business decisions, and conducting seminars and courses to train the staff to comply with the rules and objectives of the Organization, as well as, working on strengthening and supporting the skills and experiences within the business environment in order to contribute in achieving the organizational excellence through the organizational dexterity.

2. Considering the strategic alignment technique as an important variable in achieving the organizational excellence and organizational dexterity.

3. Clarifying the most significant dimensions of the organizational excellence and dexterity that should play a significant role in strengthening and supporting the strategic alignment's practices and techniques within the business environment.

\section{The Hypothetical Model of the Research}

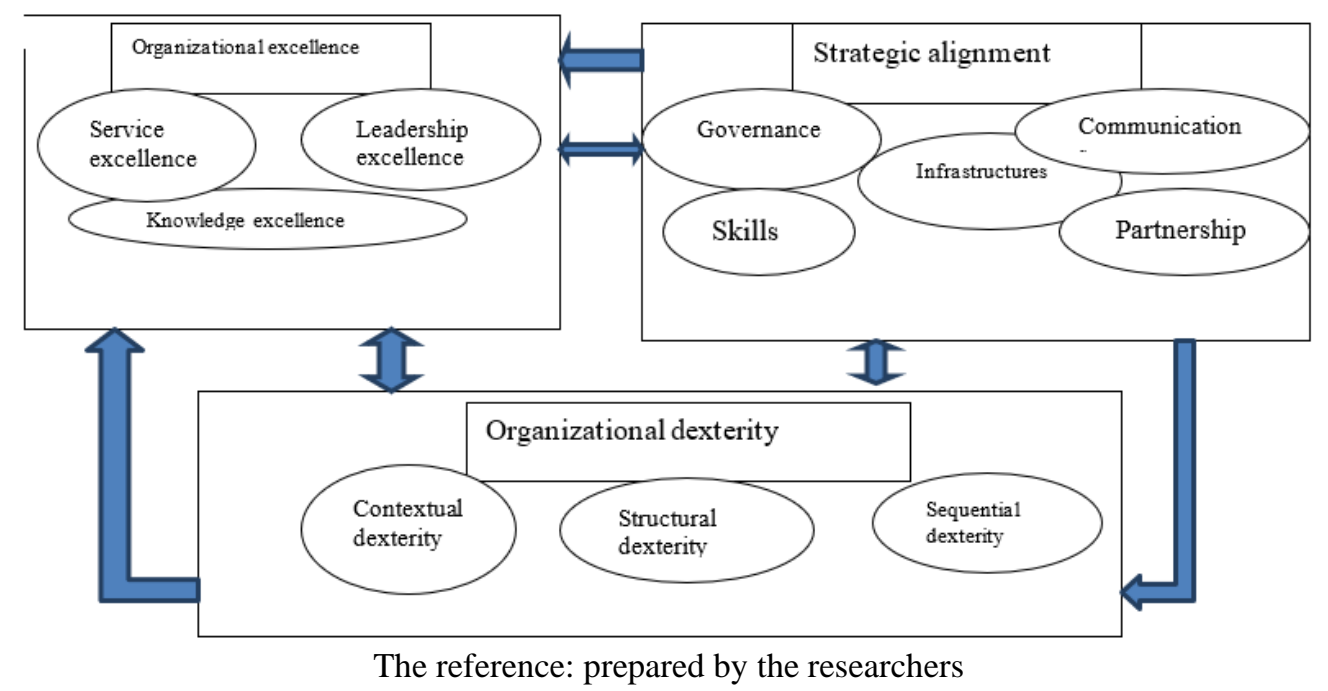

\section{Research Hypotheses}

The research hypotheses were formulated according to the hypothetical model of the research; they are going to be tested through correlations and influence to prove its validity and invalidity.

1. The first main hypothesis (there aren't any statistical correlations between the strategic alignment with its dimensions and the organizational excellence).

2. The second main hypothesis (there isn't any statistical association relationship between the strategic alignment with its dimensions and the organizational dexterity). 
3. The third main hypothesis (there isn't any statistical correlation between the organizational dexterity and the organizational excellence).

4. The fourth main hypothesis (there isn't any statistical influence between the strategic alignment with its dimensions and the organizational excellence).

5. The fifth main hypothesis (there isn't any statistical influence of the strategic alignment with its dimensions on the organizational dexterity).

6. The sixth main hypothesis (there isn't any statistical influence of the organizational dexterity on the organizational excellence).

7. The seventh hypothesis (there aren't any multiple statistical influences of the strategic alignment and the organizational dexterity on the organizational excellence).

8. The eighth main hypothesis (there aren't any indirect statistical correlations between the strategic alignments in achieving the organizational excellence through the organizational dexterity).

\section{Research Community and Sample}

The researcher has chosen Karbala University to be the study field because of its role in the society, in addition to its understanding and cooperative society in achieving researches and scientific studies. The study included four colleges of the university which are: College of Management and Economics, the College of Engineering, the College of Islamic Sciences and College of tourism. The researcher distributed (88) questionnaire form to the target sample and the retrieved were 80 under study forms; thus, the included under study sample was (80), and the retrieval percentage was $(1 \%)$.

\section{Measurements}

The strategic alignment was measured by a scale consisting of (25) items according to [1]; the scale validity was framed and tested by [3]. The questionnaire items were measured by Pentagram Likert Scale that consists of (5 items) ranging from (1) I don't seriously agree to (5) I seriously agree. The scale consists of five sub-dimensions which are: (1) communications "5 items", (2) governance "5 items", (3) partnership "5 items", (4) infrastructures "5 items", while the organizational excellence variable was measured by a scale consisting of (15 items) according to the scale of [2] it consists of three dimensions: (1) leadership excellence, (2) service excellence, (3) knowledge excellence, according to the scale (Tuchman, 2013:7); also the organizational dexterity variable was measured by a scale consisting of (15 items), and three sub- dimensions which are: (1) successive dexterity, (2) structural dexterity, (3) contextual dexterity.

\section{Theoretical Framework}

\section{Strategic Alignment}

The word (Alignment) was mentioned in (Webster Dictionary); it means lining up on a straight line; it's a co-operative agreement between some people or a group of people on a common issue or point of view. But in the business field, the association is between the organizational objectives and personal objectives of the staff; so, it requires understanding to the theses and objectives of the organization and coherence between objectives and plans to be carried out. After identifying the strategic administration's thought, we found that the strategic alignment is a main topic that the organization cares about, especially, the productive organizations that adopt the strategic alignment concept. The researcher used different terms to refer to the strategic alignment such as compatibility, proportionality, integration, and 
coherence; so, it relates to the associations between the business organizations to achieve a group of desired objectives. The strategic alignment increases the return on investments and achieves the competition and flexibility to meet the new challenges and opportunities [4], [5] assured that achieving the strategic alignment requires all the staff to unify their common purposes and visions, as well as, have the ability to understand the method of performing their individual roles that support carrying out the whole strategy of the organization by methods that enable the staff to understand and create strategic awareness through different means of communications. The organizations use methods to increase the staff strategic awareness which support their reorganization of the theses, visions and strategic objectives of the organization.

\section{Dimensions of Strategic Alignment}

The strategic alignment has main dimensions in universities; here comes an explanation for these dimensions:

\section{Communications}

The information accuracy and quality are the keys of excellence and gaining advantages over the competitors. Exchanging actions, ideas, information and the clear understanding to the main ideas of the organizations includes the successful strategies which are the main factors of increasing the strategic alignment mission. A very important issue is that the dynamic environment, that characterizes most of the organizations, includes exchanging continuous knowledge within the institutions. Many companies employ the staff that plays official communication roles between the units or does several jobs to facilitate exchanging knowledge [6]. Also (Granbier Gobaroun, 2013) thinks that communications are the exchanging process of ideas and information between the individuals and communities who work for the same organization in order to establish a common understanding to achieve common objectives.

\section{Governance}

It can be defined as the structure of relations, operations and over sighting of an institution for achieving its main objectives by adding values rather than striking a balance between risks and the return [2], [7] assured that the companies governance is a system through which we can manage the business companies and control them. The structure of the companies' governance specifies the rights and duties of both the individuals and the stakeholders in the company; it also establishes the rules and detailed procedures to take decisions concerning the commercial business and company affairs. Based on that, a structure was established to identify the objectives of the company and its methods to achieve these objectives in addition to over sighting the performance.

\section{Partnership}

It means building the exchangeable trust, communication, and co-operation in exchanging information rather than the ability to find the additional value that leads to sustainable competitiveness with common purposes to ensure achieving the strategic objectives (Kimeli, 2013). But (Gentimir, 2015) sees that the partnership is a co-operative operation that imposes a common technique or common activities. Economically, it's a plan that requires finance and modulation to achieve the common objectives as what happened before, which represents a real challenge from the common values standpoint, between the European Union and the Russian Federation. 


\section{Infrastructure}

The dictionary mentioned the definition of infrastructure as it's the base or the texture as it has recently become the strategic and main choice to enable participating in the activities and different events. It's considered as the technological framework that helps the organization satisfy the customers and meet the needs of the management as it's a group of resources and organizational abilities that provides a base to apply and developing the strategic objectives (Xia \& King, 2002:3).

\section{Skills}

The main changes in the needed skills often requires effective procedures of the high working practices, and they may increase the skills value in communication and co-operation; the organization have to get benefit from the current unused staff abilities instead of demanding development of the new skills [8]. The skill means the ability of critical thinking and evaluating the environmental conditions to be a crucial strength that could solve unexpected problems within these skills. (Suteski, 2012:2) specified the kinds of skills as (technical skills, cognitive skills, personal skills) used widely in the work practices and characterized by flexibility, innovation and effectiveness rather than independence to achieve the excellent performance.

\section{Secondly: Organizational Excellence}

In the light of the modern scientific development, especially, the rules of studying management, the intellectual contributions related to the philosophy of organizational excellence not only of the staff performance but also their abuses have been developed and included the concept of organizational excellence. The total quality management approach has been emerged and concentrated on the philosophy of excellent performance and continuous development, so these approaches should provide trust in the organization's ability to achieve the sustained success on the long run. The organizational order is associated greatly to excellent organizations, so it presents a competitive and changeable environment. The organization can't be excellent except through the strategic alignment that works on compatibility between the staff objectives and the organization objectives, the institutions invest the pre-effective strategic planned crucial opportunities with a common clear vision of the objective and the sufficiency of recourses and performance [9].

\section{Dimensions of Organizational Excellence}

The organizational excellence includes three sub- dimensions that used in the universities as follows:

\section{Leadership excellence}

The leadership excellence [10] is one of the most significant pillars of the modern management as it requires an utmost ability of the leader to be capable of keeping up with the developments and changes imposed by the knowledge era. There's no doubt that leaders who can't confess inefficiency and problems in all situations; they may have the opportunity to increase competition which may push them towards excellence. The importance of the leadership excellence in the academic institutions results from the complicated and ambiguous business nature of the universities [11].

\section{Service Excellence}


Authors [12] identified the service excellence as the organized abilities to introduce continuous advice for the distinctive customers. These abilities are related to all the activities inside the organization and it doesn't only include the customer services department, but also the other employees contributing specially in achieving the service excellence. It's one of the main challenges that face the organization on the strategic, technical, and operational levels; it reflects four main organizational dimensions which are: the strategic, cultural, creative and operational dimensions. The service is characterized by introducing unique characters that express great satisfaction resulted from the good and surprising performance. Thus, the service organization doesn't need only to satisfy the customers, but also it should make them happy because happiness is always a result of excellent service that exceeds expectations [13].

\section{Knowledge excellence}

The knowledge management $(\mathrm{KM})$ has become a very important matter in the academic institutions which motivates the ability to gather and analyze data and transform it into knowledge, and then apply and strengthen it. The knowledge has become a strategic, main, and necessary resource for flourishing and competitiveness. In the light of globalization and the knowledge economy, the knowledge lies in innovation and creation which are the main elements of the competitiveness ability. Using the knowledge management (KM) will achieve important benefits in the educational institutions for developing the curriculum, students' and graduates' services, administrative services, as well as, strategic planning (Pinto, 2014:2). [14] assured that knowledge is the modern root for evaluating, spreading, storing and using the educational processes. Knowledge management has become a strategic solution as it participates effectively and uses the human efficiency, experiments, experiences, skills, talents and ideas rather than intuition, commitments, innovations, practices and imagination then merging them as sources of information that the organization uses to achieve its strategic objectives. Thus, the educational society should host the knowledge excellence as a strategy used for carrying out its organizational philosophy and operations in the educational institutions.

\section{Organizational Dexterity}

The history of researches dealt with the organizational dexterity goes back to [15] who was the first used the word "dexterity" in the business works as a structural perspective of this concept. He suggested it as a double organizational structure for the companies that look forward to innovation. it has two sections: the first section is starting or developing creative activities which means discovering innovation; the other section is carrying out or spreading creative activities which means getting benefits of innovation. He explained "dexterity" as a serial concept that the organizations use to discover or abuse in the same time but on long terms between the two methods. [16] Refers to the challenge that the organization may face on the long run which seems successful according to the recent greatly increasing of the uncertain economic cases, as the ability of adaptation concentrating on fast movement towards new opportunities and modifications of changeable markets is a very important matter. It means that the successful companies shouldn't only search for new opportunities, but they also should be capable of abuse the assets (properties) values; this capacity provides great compatibility [17] which means enabling the companies to achieve balance between discovering and abusing to achieve sustained competitiveness through which the organizational dexterity existed [18], [19] think that the organizational dexterity is the organization ability to discover and abuse its internal and external resources at the same time to meet the daily business needs, as well as, adapt with the future markets' changes. But (David, 2016:43) refers to the organizational dexterity as the company's ability to managing the education at the same time within double workshop and one workshop in gradually and radical searching and innovating field, as well as, stability and transformation of organizational adaption. 


\section{Dimensions of Organizational Ambidexterity}

The organizational dexterity has three sub-dimensions used by the universities which are:

\section{Sequential Ambidexterity}

The organizations developed through changes and sequential adaptations with environmental transformations by reorganizing the structures and the operations [20], [21] assured that the excellent organization can reorganize its structure because of the changeable environmental conditions; according to this change, it can develop its strategies and objectives which enable it to adapt with the environment in order to discover and invest environmental opportunities to match the market variables. Facing these changes, the theory of balance between the organization and the environmental changes should be formulated; it is necessary to achieve the balance between the structures and redesigned its operations and the environment through serial and sequential operations according to the time as the more excellent the organization is, the greater ability to adapt with time and the current environmental change it has and the much capacity to achieve the sustained competitiveness it has.

\section{Structural or Simultaneous Ambidexterity}

The structural side is still the most spreading side of the organizational dexterity. This concept depends on the organizational designs that are separated from the concurrent or simultaneous activities with separating the discovering and obsessive structures into independent units that require leadership, integration and coordination of the high management in the organization. The structural or simultaneous dexterity is a means of achieving the balance between discovering, abusing and preferring by using sub-organizational units that are separated but strategically integrated with the different systems, efficiencies, motivations, operations and cultures [20]. The structural dexterity is achieved through developing some structural mechanisms in order to deal with the competitive requirements that face the organization to achieve compromise and adaptation [17], [21] thinks that the organizations follow-up several methods in achieving the balance between discovering opportunities and abusing them through following an integrated method and concentrating on efficiencies, systems, motivations, operations and cultural programs inside the organization rather than strategic plans on the organizational structural level and working on establishing a comprehensive group of values that concentrates on the key of organizational dexterity represented by the organization ability to invest new opportunities through discovering and abusing at the same time.

\section{Contextual Ambidexterity}

The contextual dexterity in the field of changeable business refers to the best way to achieve dexterity through building context of business unit to encourage people to participate in both discovering and abusing instead of the structural separating; this model decreases the costs of coordination and facilitates organizing and adaptation as [17] has referred to. There should be a management in order to establish the double structural order, as it's expected that the leader may creat a context of business unit in systems, operations and beliefs. This kind of techniques is individually in the organization. The successful management is expected to establish a balance between (discipline, supporting and trust) within the organizational contexts. But [22] mar think that the contextual dexterity is the behavioral ability to establish the compatibility and adaption at the same time within the whole business unit; it's also the ability that enables the unit/organization to achieve the balance between discovering and abusing. The organizational context is characterized by interacting through supporting, discipline, and trust [21]. 


\section{The Practical Aspect of the Research}

\section{Analyzing and Testing the Research Hypotheses}

\section{Describing the search tool}

In order to get information about the study variables, we need preparing a questionnaire including two parts: the first part includes (5) items about the demographic properties of the research sample that represents the shifting variables that affects the respondents replies on the questionnaire items of general information about (age, gender, working years, scientific title, career qualification), while the second part of the questionnaire includes (50) items distributed on the study variables, the items related to the study, (strategic alignment, organizational excellence, organizational dexterity). The items were distributed by (4) items and (5) items on the study variables. The questionnaire form depends on a primarily tool; to gather the study data; a group of techniques such as (content validity) The stability refers to the ability of the form to gather the same results if we repeat the research by using the same tool on the same sample. The stability was proven through stability factor as shown in (Cronbach Alhpa) by using the method of internal coherence. The results in table 2 refer that Cronbach Alpha factor for all the scale items was higher than the acceptable minimum rate. It refers to the coherence between items.

\section{Demographic characteristics of the research sample}

Table 1. Descriptive Statistics $(\mathrm{N}=80)$

\begin{tabular}{|c|c|c|}
\hline Demographic characteristics & The number & Ratio \\
\hline \multicolumn{3}{|l|}{ 1- Gender } \\
\hline Female & 5 & $\% 6.25$ \\
\hline Male & 75 & $\% 93.75$ \\
\hline \multicolumn{3}{|l|}{ 2- Age } \\
\hline Under 30 & 25 & $\% 31.25$ \\
\hline $31-45$ & 33 & $\% 41.25$ \\
\hline More than 46 & 22 & $\% 27.5$ \\
\hline \multicolumn{3}{|l|}{ 3- Scientific title } \\
\hline Assistant Lecturer & 15 & $\% 18.75$ \\
\hline Lecturer & 35 & $\% 43.75$ \\
\hline Assistant Professor & 22 & $\% 27.5$ \\
\hline Professor & 8 & $\% 10$ \\
\hline \multicolumn{3}{|l|}{ 4- Qualification } \\
\hline M.A & 25 & $\% 31.25$ \\
\hline Ph. D & 55 & $\% 68.75$ \\
\hline \multicolumn{3}{|l|}{ 1- Years of service } \\
\hline From 5 to 10 years & 25 & $\% 31.25$ \\
\hline From 11 to 15 years & 20 & $\% 25$ \\
\hline More than 15 years & 35 & $\% 43.75$ \\
\hline
\end{tabular}

Social Gender: From table (1), it's obvious that most of the sample is males as their percentage was about $93.75 \%$ which means about 75 males. But females were 5 with percentage $6.25 \%$, which is obviously greatly less than the male's percentage. Age: A percentage of $31.25 \%$ which means 25 persons of the sample were fewer than 30 years. But the sample ages between (31-40 years) had the highest percentage (41.25\%) as they were 33 people. Scientific Title the numbers of persons titles (Assistant Teacher) was (15) with the less percentage 
$(81.75 \%)$. The persons titled (Teacher) were (35) with the highest percentage $(43.75 \%)$. The numbers of persons titled (Assistant Professor) was (22) with the percentage (27.5\%). Finally, the persons titled (Professor) were (8) with the percentage (10\%). Scientific Qualification: The results mentioned in table (2) refers that the vast majority of the sample, 55 persons, have $\mathrm{PhD}$ with the percentage (75.68\%). (25 persons) have Master's degree with percentage $(25.31 \%)$ These percentages show that the respondent sample has the ability and efficiency to understand the questionnaire items which positively reflects on the final results of the research. The Service Years: The percentages mentioned in table (1) refers that the highest percentage was of those whose services in the university were about (more than 15 years) they were ( 35 persons) with percentage $(43.75 \%)$ of the study sample. The lowest percentage was of those whose services in the university was (less than 15 years) with percentage (25), they were (20) persons. The number of persons whose services in the university were (5-10 years) was (25) with percentage $(31.25 \%)$. These percentages obviously refer that the university has high academic experts.

Table 2. Cronbach's alpha values

\begin{tabular}{|c|c|r|}
\hline Cronbach's alpha & number of paragraphs & search variables \\
\hline 0.887 & 20 & Strategic alignment \\
\hline 0.906 & 15 & Organizational Excellence \\
\hline 0.930 & 15 & Organizational ingenuity \\
\hline
\end{tabular}

* The Statistical Validity and Reliability Test of the Research Scale

\section{The Statistical Description of the Research Variables}

This item aims to know the dimension levels of the study represented by (strategic alignment, organizational excellence, and organizational dexterity) by using the arithmetical mean and standard deviation; the questionnaire form adopted the pentagram (Lekirt Scale) (I agree intensively, I don't intensively agree); as every variable has an hypothetical arithmetical mean less than(3) is rejected. The independent variable (strategic alignment) has an arithmetical means about (3.744), and the standard deviation was (0.395), and the centigrade weight was (74.88), The arithmetic mean of the organizational dexterity variable was (3.744), and its standard deviation was (0.395), the centigrade weight was $(71.0 \%)$.

Table 3. Means, standard deviations, Percentage, order of dimensions $(\mathrm{N}=80)$

\begin{tabular}{|c|c|c|c|c|}
\hline Variables & Means & S.D. & Percentage & order of dimensions \\
\hline $1 . \mathrm{X}$ & 3.744 & .395 & $\% 74.88$ & 1 \\
\hline $2 . \mathrm{Z}$ & 3.550 & .494 & $\% 71.0$ & 3 \\
\hline $3 . \mathrm{Y}$ & 3.635 & .481 & $\% 72.7$ & 2 \\
\hline
\end{tabular}

Note $* * \mathrm{p}<.01$.

\section{The Correlations Hypotheses of the Key Search Variables Test}

This part of the research is specified to a statistical show through which we can test and analyze the correlation between the key research variables (strategic alignment, organizational excellence, and organizational dexterity), it will be mentioned according to the research hypothesis planning as follows:

Table 4. The correlation matrix for the main search variables $(\mathrm{N}=80)$

\begin{tabular}{|l|c|c|c|c|}
\hline \multicolumn{1}{|c|}{ Variables } & $\mathbf{1}$ & $\mathbf{2}$ & $\mathbf{3}$ & Sig.(2-tailed) \\
\hline 1 X Strategic alignment & & & & 0.000 \\
\hline 2 Z Organizational Ambidexterity & $0.785^{* *}$ & & & 0.000 \\
\hline 3 Y Organizational Excellence & $0.792^{* *}$ & $0.840^{* *}$ & & 0.000 \\
\hline
\end{tabular}

Note $* * p<.01$.

1. The first key hypothesis test: it provides that there isn't any moral relationship between the strategic alignment with its dimensions and the organizational excellence). The data mentioned 
in table (4) refer to a positive and moral correlation if the coefficient correlation factor is 0.792 at the moral level $(1 \%)$ which refers to the validity and acceptance of the hypothesis.

2. The second key hypothesis test: (there's no moral correlation between the strategic alignment with its dimensions and the organizational dexterity). The data mentioned in table (4) refers to moral and positive correlation if the coefficient is $(0.785)$ at the moral level $(1 \%)$ which refers to the validity and acceptance of the hypothesis.

3. The third key hypothesis test: (there's no moral correlation between the organizational excellence with its dimensions and the organizational dexterity). The data mentioned in table (4) refers to moral and positive correlation if the coefficient is $(0.840)$ at the moral level $(1 \%)$ which refers to the validity and acceptance of the hypothesis.

Secondly: The results of the influence relations between the research variables

According to this item, the hypotheses are tested in order to investigate their validity, so the simple linear regression was used rather than (R2) to measure what the variables stand for which affects the organizational dexterity.

A - The fourth key hypothesis test: There's no moral influence between the strategic alignment and the organizational excellence. Table (5) shows the coefficient analyzing model of the regression used to measure the impacts of strategic alignment on the organizational excellence. Table (5) is for testing and identifying the impacts of strategic alignment on the organizational excellence according to the following regression equation $y=a+b(x)$.

1. $\mathrm{R} 2$ value was $(0.627)$ which means that the strategic alignment contributed in achieving the organizational excellence with percentage (0.627) of the changes that may occur to the organizational excellence, but the remaining percentage returns to other variables involved in the model which explained the morality and strength of this model.

2. The regression coefficient of the strategic alignment in achieving the organizational excellence was $(0.792)$ which is a moral value which supports the calculated $(\mathrm{t})$ value of the regression coefficient which was (11.450), it's a moral value at the moral level $(1 \%)$ which proves the validity and acceptance of the hypothesis.

Table 5. Organizational Excellence and Relations of Influence between Strategic Alignment

\begin{tabular}{|c|c|c|c|c|c|r|}
\hline OE & (a) & $\boldsymbol{\beta}$ & $\begin{array}{c}\text { Regression } \\
\text { coefficient }\end{array}$ & (t) & F & R2 \\
\hline SA & .0270 & .9640 & .7920 & 11.450 & 131.103 & .6270 \\
\hline
\end{tabular}

Note, $\mathrm{p}<.01$.

B - The fifth key hypothesis test: in order to test this hypothesis, the researcher used the regression coefficient including (f) test, beta coefficient (B), R2 and (t) test to identify the impacts of strategic alignment on the organizational dexterity as in table (6):

From table (6), it's obvious that R2 was (0.617) which means that the strategic alignment contributed in achieving the organizational dexterity with percentage $(0.617)$ of the changes occurred to the organizational dexterity. But the remaining percentage returns to the other variables involved in the model which explains the morality and strength of this model. The regression coefficient of the strategic alignment in achieving the organizational dexterity was $(0.785)$ which is a moral value which supports the calculated $(\mathrm{t})$ value of the regression coefficient which was (11.202) which was greater than the tabulated value that was (1.296), it's a moral value at the moral level $(1 \%)$ which proves the validity and acceptance of the hypothesis.

Table 6. Organizational Ambidexterity and table (6) Relations of Influence between Strategic Alignment

\begin{tabular}{|c|c|c|c|c|c|c|}
\hline OA & (a) & $\boldsymbol{\beta}$ & $\begin{array}{c}\text { Regression } \\
\text { coefficient }\end{array}$ & (t) & F & R2 \\
\hline SA & $-0.125-$ & .982 & .785 & 11.202 & 125.475 & .617 \\
\hline
\end{tabular}

Note, $\mathrm{p}<.01$. 
C - The Sixth Key Hypothesis Test: in order to test this hypothesis, the researcher used the regression coefficient including (f) test, beta coefficient (B), R2 and (t) test to identify the impacts of organizational dexterity on the organizational excellence as in table (7):

It's obvious that R2 was (0.706) which means that the organizational dexterity contributed in achieving the organizational excellence with percentage $(0.706)$ of the changes occurred to the organizational excellence. But the remaining percentage returns to the other variables involved in the model which explains the morality and strength of this model. The regression coefficient of the organizational dexterity in achieving the organizational excellence was (0.982) which is a moral value which supports the calculated $(t)$ value of the regression coefficient which was (0.840) which was greater than the tabulated value that was (1.296), it's a moral value at the moral level $(1 \%)$ which proves the validity and acceptance of the hypothesis.

Table 7. Relations of Influence between organizational Excellence and Organizational Ambidexterity

\begin{tabular}{|c|c|c|c|c|c|c|}
\hline OA & (a) & $\boldsymbol{\beta}$ & $\begin{array}{c}\text { Regression } \\
\text { coefficient }\end{array}$ & (t) & F & R2 \\
\hline OE & .730 & .818 & .840 & 13.697 & 187.613 & .706 \\
\hline
\end{tabular}

$\mathrm{p}<.01$. Source: Researchers based on the results of the electronic

D - The Seventh Key Hypothesis Test (8) there's no multi statistical impacts of both the strategic alignment and the organizational dexterity on the organizational excellence). The researchers used the multi regression method for testing the mentioned hypothesis by using the statistical program (SPSSV.21). The following table shows the multi regression coefficients:

Table 8. Decomposition directed effects (Multiple Regression,) X, Y, Z

\begin{tabular}{|c|c|c|c|c|c|}
\hline & \multicolumn{2}{|c|}{$\begin{array}{c}\text { Organizational } \\
\text { Excellence Y }\end{array}$} & $\begin{array}{c}\text { (t) Regression } \\
\text { coefficient }\end{array}$ & $\begin{array}{c}\text { (F) Regression } \\
\text { coefficient }\end{array}$ & R Square \\
\cline { 2 - 3 } & $\mathbf{A}$ & $\mathbf{b}$ & & 116.544 & 0.752 \\
\hline Strategic alignment X & 0.096 & 0.419 & 3.750 & & \\
\cline { 1 - 1 } $\begin{array}{c}\text { Organizational } \\
\text { Ambidexterity Z }\end{array}$ & & 0.555 & 6.218 & & \\
\hline
\end{tabular}

$\mathrm{p}<.01$. Source: Researchers based on the results of the electronic

The table shows that the regression coefficients of the strategic alignment after interaction with the organizational dexterity on the organizational excellence are $(0.555,0.419)$ in order, both of them are moral at the level (0.01). (f) Value that measures the regression model morality was generally (116.455), it's a moral value at the level (1\%); R2 value was $(75.2 \%)$ which means that the interaction between the two variables explains about $(75.2 \%)$ of the occurred changes of the following variables. But the remaining percentage returns to the other variables involved in the model. If we compare the final results of the mentioned multi regression model with the results of the regression model that measures the approved and average variable in the organizational excellence separately, we find out that $\mathrm{R} 2$ of both of them according to the tables $(7,8)$ were $(0.617 \%)$ and $(.0706 \%)$ in order; the $\mathrm{R} 2$ of both of them were less than the R2 resulted from the interaction between them. The researcher concluded from the mentioned results the validity of the seventh hypothesis.

D - The Eighth Hypothesis Test (indirect influence): there's no indirect statistical influence of the strategic alignment in achieving the organizational dexterity. For testing this hypothesis, the researcher tested the average role of the organizational dexterity variable by using (Baron \& Kenny, 1986:1176) which is a common method in testing the direct and indirect influences of the independent variables on the approved variables in the existence of average variables. 
In order to test the average organizational dexterity variable between the strategic alignment and organizational excellence, we notice from table (9) the morality of regression model related to the strategic alignment if the beta value is $(0.419)$ with morality less than $(0.01)$ and the R2 is $(0.752)$ which assures the morality of the regression model which means achieving the seventh hypothesis with percentage $(100 \%)$, thus, the organizational dexterity variable goes between the strategic alignment and the organizational excellence.

Table 9. Indirect effects $X, Y$

\begin{tabular}{|l|c|c|c|c|}
\hline Organizational Excettence $\mathbf{Y}$ & $\boldsymbol{\beta}$ & $\mathbf{R}^{\mathbf{2}}$ & $\Delta \mathbf{R}^{\mathbf{2}}$ & Sig. \\
\hline Strategic alignment X & .419 & .752 & .125 & 0.00 \\
\hline
\end{tabular}

$\mathrm{p}<.01$. Source: Researchers based on the results of the electronic

\section{Conclusions and Recommendations}

The analyzing results show that the strategic alignment has an important role in establishing the concept of organizational dexterity for the professors in the searched universities, as well as, the sustainability of approving the organizational excellence in order to face different challenges. the strategic alignment represents a group of techniques and qualities that aim to achieve the organizational excellence and encourage the professors to innovate and transforming to find out new processes of discovering and investing the available energies. results clarify that there's a positive correlation between the strategic alignment and the organizational dexterity which refers to the topics originality and interactions between them. results refer to the impacts of strategic alignment on the organizational dexterity that was (79.2\%) which refers to the sample's interests of developing and improving the educational level from one side, and resources and abilities investments, as well as, following- up elegant techniques in the organizational dexterity from the other side.

Although the under-study universities tried to open up to the local community to achieve excellence in their businesses through building a balanced social relationship to meet the needs of business market and bear their social responsibilities.

\section{Recommendations}

The academic institutions are sources of scientific and intellectual enlightenments as it's necessary to find out the concepts, compatibility and co- operation in different fields to improve the educational reality in order to strengthen the strategic alignment techniques. It's necessary to keep the values and principles and establishing an encouraging business environment for the organizational excellence in order to invest new abilities to provide the students with future skills. We should crystallize a new social reality to overcome the conflicts and contradictions through the balance between discovering new abilities and investing the current possibilities. Increasing the critical thinking in formulating strategies matching with the highly competitive fields to strengthen the organizational excellence and concentrating on the strength of the resources (talents, patents, copy rights, highly competitive possibilities).

\section{REFERENCES}

1. Luftman, J-(2014). Strategic Alignment Maturity, Global Institute for IT Management, Fort Lee, New Jersey.

2. Abu Naser S.S., Al Shobaki, M.J. (2017). Organizational Excellence and the Extent of Its Clarity in the Palestinian Universities from the Perspective of Academic Staff. International Journal of Information Technology and Electrical Engineering, ITEE, 2017, 6 (2), pp.47-59. ffhal-01522415f. 
3. AL-Adwan, Minwer, M., (2014), "The Impact of Strategic Alignment Maturity of Business and Information Technology on Performance: Case Study of Jordan Public Sector Organizations”, Journal of Basic and Applied Scientific Research www.textroad.com.

4. Selen, W., Ogulin, R. (2014) Strategic Alignment across a Tourism Business Ecosystem, Athens Journal of Tourism - Volume 2, Issue 3 - Pages 167-178.

5. Kaplan, R. S., Norton, D. P. (2004). Strategy maps: Converting intangible assets into tangible outcomes. Harvard Business Press.

6. Luftman, J., Brier, T. (1999) Achieving and Sustaining Business-IT Alignment, Calirfornia Management Review.

7. Kocmanová, Alena, Jiří Hřebíček, Marie Dočekalová, (2011), Corporate Governance and Sustainability, Economics and Management.

8. Martin B., Healy J. (2009), "Changing Work Organization and Skill Requirements”. Article, Vol 35 No. 3.

9. Pinar, M., \& Girard, T. (2008). Investigating the Impact of Organizational Excellence and Leadership on Business Performance: An Exploratory Study of Turkish Firms. SAM Advanced Management Journal, 73(1), pp. 29-45.

10. Borghini, S. (2005). Organizational creativity: Breaking equilibrium and order to innovate. Journal of Knowledge Management, 9(4), pp. 19-33.

11. Abu Naser, S. S, Al Shobaki, M. J. (2017) "Organizational Excellence and the Extent of Its Clarity in the Palestinian: Universities from the Perspective of Academic Staff”, ITEE Journal, Vol. 6, No. 2, pp. 1016.

12. Thomassen, J.P., de Haan, E. (2016) "How to create a service excellence organization" White paper about the European service excellence model and the European technical specification CEN/TS $16880-$ Creating outstanding customer experiences through service excellence.

13. Aziz, Y.A. \& Wahiddin, K. (2010). Conceptualising the service excellence and its antecedents: the development of the. structural equation model. Journal of Tourism, Hospitality \& Culinary Arts, Vol. 2, No. 1, pp. 1-13.

14. Nikolaus S. (2011) Knowledge Management in Education in Indonesia: An Overview, Global Journal of human social science, Vol.11, Issue 1.

15. Duncan, R. B. (1976). The ambidextrous organization: Designing dual structures for innovation. In R. H. Kilmann, L.R. Pondy and D. Slevin (eds.), The management of organizationdesign: Strategies and implementation. New York: North Holland: pp. 167-188.

16. Tushman, Michael L. and O'Reilly, Charles A. (1996). The ambidextrous organization: managing evolutionary and revolutionary change. California Management Review, 38: pp. 3-43.

17. Birkinshaw, J., Gibson, C. (2004), "Building ambidexterity into an organization". MIT Sloan Management Review, 45(4), pp. 47-55.

18. Chaharmahali, Sara Mirzataghi \&Siadat Seyed Amir, (2010), "Understanding and explaining ambidextrous organizations", Master Thesis, Linköping University Department of Management and Engineering Strategic Management in International Organizations Spring.

19. Fu, Na; Patrick C. Flood; Tim Morris, (2014), "Organizational ambidexterity and professional firm performance: the moderating role of organizational capital", Journal of Professions and Organization, 3, pp. 1-16 doi: 10.1093/jpo/jov010 Advance Access Publication Date: 22 January.

20. Tarody, D. (2016), "Organizational Ambidexterity as A New Research Paradigm in Strategic Management”, Xlvii. Évf, 5. Szám/Issn 0133-0179 39.

21. O'Reilly, C. A., \& Tushman, M. L. (2013, June). Organizational ambidexterity: Past, present and future (Research Paper No. 2130). Stanford Research Paper Series.

22. Raisch, S., \& Birkinshaw, J. (2008). Organizational Ambidexterity: Antecedents, Outcomes, and Moderators. Journal of Management, 34(3): pp. 375-409.

\section{Article history:}

- $\quad$ Received 25 May 2019

- Accepted 28 Juny 2019 